\title{
The Value of Adenomyosis Type in Clinical Assessment: A Single-center Experience of 755 Nodular and Diffuse Adenomyosis Cases
}

\author{
Gulsah Selvi Demirtas, $M^{1 *}{ }^{*}$; Ibrahim Uyar, MD $^{2}$ \\ 'Tepecik Education and Research Hospital, Department of Gynecologic Oncology, İzmir, Turkey \\ ${ }^{2}$ Tepecik Education and Research Hospital, Department of Gynecology and Obstetrics, İzmir, Turkey
}

\begin{abstract}
Background: To investigate the incidence of nodular and diffuse adenomyosis, concomitant pathologies and also to compare the demographic and clinic differences among patients with adenomyosis and their surgery indications.

Methods: This retrospective study was conducted in Tepecik Research Hospital, Izmir, Turkey between 2014 and 2016. Patients were divided into two groups of nodular and diffuse adenomyosis. The following variables were evaluated for both groups: age, gravidity, parity, menopausal status, indication for hysterectomy, ultrasonographic parameters, gynecological symptoms (abnormal uterine bleeding $[A \cup B]$, pelvic pain and pelvic pressure, postmenopausal vaginal bleeding), preoperative and postoperative histopathological assessment, and coexisting pathologies.

Results: Of the total 3457 cases of hysterectomies, 755 (95\% Cl: 20.4-23.1) were confirmed with adenomyosis. There were 217 (95\% Cl: 23.9-30.0) postmenopausal women. Adenomyosis was most commonly detected in patients in the age of 40 to $50(57.6 \%)$. The most common symptoms were AUB ( $\mathrm{n}: 336)(95 \% \mathrm{Cl}: 40.9-48.0)$, pelvic pain or pressure (n:139) (18.4\%), and postmenopausal vaginal bleeding (n: 119) $(95 \%$ Cl: 13.1-18,4). Seventy-four (95\% Cl: $7.9-11.9)$ of the patients had nodular and 681(95\% Cl: 88.0-92.3) had diffuse adenomyosis. Demographic data, age, parity, gravidity, endometrial thickness, and menopausal status were similar between the groups. AUB was more frequently detected in nodular adenomyosis (56.8\%). Myoma uteri was the main hysterectomy indication in both groups. In addition, treatment-resistant AUB for nodular adenomyosis and endometrial pathologies for diffuse adenomyosis were the most frequent indications for hysterectomy after myoma uteri.

Conclusion: The most common form of adenomyosis was the diffuse form. Endometrial pathologies were more frequently associated with diffuse adenomyosis. Asymptomatic and incidental adenomyosis were more common with the diffuse form. AUB was more frequently detected with nodular adenomyosis.

Keywords: Diffuse adenomyosis, Hysterectomy, Nodular adenomyosis

Cite this article as: Demirtas GS, Uyar I. The Value of Adenomyosis Type in Clinical Assessment: A Single-center Experience of 755 Nodular and Diffuse Adenomyosis Cases. Arch Iran Med. Arch Iran Med. 2021;24(5):374-382. doi: 10.34172/aim.2021.54
\end{abstract}

Received: July 2, 2020, Accepted: February 27, 2021, ePublished: May 1, 2021

\section{Introduction}

Adenomyosis is an important clinical phenomenon in gynecology, often resulting in hysterectomy due to leiomyomaindication. The presence of ectopic endometrial glands within the myometrium was first described in 1860 by Rokitansky. ${ }^{1}$ The first distinction between adenomyoma and diffuse adenomyoma was described by Cullen in 1908. ${ }^{2}$ An adenomyoma is considered as a focal form of adenomyosis and may be difficult to distinguish from uterine leiomyoma that may mimic its clinical and imaging characteristics. The term 'adenomyosis' was used for the first time by Franklin in 1925. ${ }^{3}$ Today, it is appropriate to use the definition of 'presence of endometrial glands and stroma located haphazardly and deep within the myometrium with adjacent smooth muscle hyperplasia' for adenomyosis. ${ }^{4}$ Adenomyoma should be differentiated from other myometrial conditions. Establishing the correct diagnosis is essential before surgery to avoid unnecessary interventions and to assess alternative non-surgical treatments. ${ }^{5,6}$ Although uterineconserving modalities are also possible for the treatment of leiomyomas, hysterectomy is the definitive treatment for adenomyosis. Since adenomyosis and leiomyoma commonly coexist in the same uterus, this causes a clinical dilemma for defining these conditions based on the patient's symptoms. ${ }^{7,8}$ Adenomyosis is a disorder that is diagnosed clinically. Therefore, clinical suspicion is very important. On the other hand, we can detect adenomyosis with a low rate, ranging between $2.6 \%-26 \%$, by using only clinical symptoms. ${ }^{9}$

The incidence of adenomyosis is quite lower in patients younger than 40 years of age. Therefore, magnetic resonance imaging (MRI) or 3D USG for preoperative patients seem to be reasonable both due to technical and financial reasons. Radiological advancements are promising; however, since the studies include meticulously selected patient groups and radiologic diagnostic methods cannot be applied to every patient in the clinical practice, 
adenomyosis patients are generally overlooked. We believe that clinical or radiologic distinction of diffuse and nodular adenomyosis at young ages would help to guide the type of operation and the use of preoperative diagnostic methods more liberally. Adenomyoma and myoma are technically quite different. Leiomyomas are surrounded by a pseudocapsule. This capsule facilitates the excision of leiomyoma. On the other hand, in adenomyomas, excision is often challenging due to the absence of a pseudo-capsule.

Today, the current literature has focused on especially the pre-operative and differential diagnosis of adenomyosis. To our knowledge, there are not adequate studies in the literature about the clinical differences of nodular and diffuse adenomyosis in a large case series. Based on earlier studies, first of all, we hypothesized that determining the differences of nodular and diffuse forms of adenomyosis may help clinicians in the management of these patients. Second, being aware of the clinical features of nodular and diffuse adenomyosis may facilitate patient selection for radiologic assessment. In light of the current literature, we aimed to investigate the incidence of nodular and diffuse adenomyosis, concomitant myometrial and endometrial pathologies and, also to compare the demographic and clinical differences of patients with adenomyosis and their surgery indications.

\section{Materials and Methods}

This was a retrospective study, conducted at Tepecik Research Hospital, Izmir, Turkey between 2014 and 2016. All hysterectomy cases during a period of two years were reviewed. All approvements were obtained from the hospital management and education coordination board for the study. Records from 3457 patients who underwent hysterectomy for various indications (menometrorrhagia resistant to treatment, uterine leiomyomas, pelvic organ prolapsus, endometrial hyperplasia, adnexal masses, endometrial cancer) were examined retrospectively by the same author. Patients who underwent hysterectomy and whose histopathological evaluation was evaluated in our hospital, and patients with a final histopathological diagnosis of adenomyosis were included in the study. A total of 755 patients with a final histopathological diagnosis of adenomyosis were included and 2702 patients with other diagnoses were excluded from the study. All histopathological reports were reviewed in details. Preoperative and postoperative associated pathologic features were also recorded.

Patients were divided into two groups as nodular adenomyosis and diffuse adenomyosis. The following variables were examined for both groups: age, gravidity, parity, menopausal status, indications for hysterectomy, ultrasonographic data, presence of main symptoms (abnormal uterine bleeding [AUB], pelvic pain and pelvic pressure, postmenopausal vaginal bleeding), preoperative and postoperative pathologic information, and coexisting pathologies. Since the data of all patients were recorded at the time of registration, there was no missing data for these variables. We took into account the main complaint, which bothered the patient the most.

All histological materials were evaluated by three gynecologic pathologists. They all used identical criteria for adenomyosis. The diagnostic criteria were the presence of endometrial glands and stroma within the myometrium. The cut-off point was $2 \mathrm{~mm}$ for glandular extension below the endometrial-myometrial junction. Focal adenomyosis was described as a distribution of endometrial glands and stroma locally or conglobation in the myometrium. Diffuse adenomyosis was described as distribution of endometrial glands and stroma diffusely.

Data were coded and entered into SPSS database. Statistical analysis was performed using SPSS software 16 (SPSS Inc, Chicago, IL, USA). For categoric variables, frequency counts and percentages were used. Standard deviations and medians were reported for continuous variables. Statistical analysis was performed to assess possible associations between groups using the chi-square test. The Pearson chi-square test or Fisher exact test, as appropriate, were performed for nominal or categoric variables.

\section{Results}

\section{Demographic Results}

Of the patients $(n=3457)$ who underwent hysterectomies due to various gynecological indications, 755 (95\% CI: 20.4-23.1) with a definitive histopathologic diagnosis of adenomyosis were included in this study. Seventy-four (95\% CI: 7.9-11.9) of the patients had nodular and 681 (95\% CI: 88.0-92.3) had diffuse adenomyosis. The mean age of the patients was found to be $50 \pm 5.7$ (min-max, $35-77$ ), the mean number of gravidity was $4.2 \pm 2.4$ (minmax, $0-16)$ and the mean number of parities was $2.9 \pm 1.4$ (min-max, 0-8) (Table 1). Of the patients, 538 (95\% CI: 67.9-74.4) were premenopausal and 217 (95\% CI: 23.930.0 ) were postmenopausal. The mean age of the patients was found to be $47.3 \pm 3.3$ years in the premenopausal group and $56.6 \pm 4.9$ years in the postmenopausal group. No statistically significant difference was found between the diffuse and nodular adenomyosis groups in terms of age, gravidity, parity and endometrial thickness (Table 1).

\section{Clinical Results}

The most common complaints on admission were AUB (n: 336) (95\% CI: 40.9-48.0), pelvic pain and sense of compression (n: 139) (95\% CI: 15.6-21.1) and postmenopausal vaginal bleeding (n:119) (95\% CI: 13.1-18.4). Of the patients, 161 (95\% CI: 18.3-24.2) were asymptomatic (Table 2). AUB was significantly more common in the nodular adenomyosis than diffuse adenomyosis patients $(P=0.026)$. The rate of asymptomatic adenomyosis in the diffuse group was higher than that in the nodular adenomyosis [22.9\% (95\% CI:19.7-26.0) vs. 6.7\% (95\% CI: 1.0-12.3)] $(P=0.001)$ (Table 2). When the 
patients with pure nodular adenomyosis (excluding other uterine and endometrial pathologies) were compared to nodular adenomyosis cases concomitant with other pathologies, the pure nodular group was found to have significantly higher preoperative pelvic pain than that of the concomitant group [29\% (95\% CI: $13.0-44.9)$ vs. 9.3\% (95\% CI: 0.62-17.9)] $(P=0.028)$ (Table 3).

\section{Radiologic Assessment Results}

Ultrasonographic findings regarded as suggestive of adenomyosis (including abnormal myometrial echogenicity, globular enlargement of the uterus, asymmetric enlargement of the anterior or posterior wall of the uterus and nodular structures in the endometrialmyometrial transition line) were found in 274 patients (36.3\%). Loss of myometrial homogeneity was found to be the most prominent ultrasonographic feature in patients with adenomyosis.

\section{Surgery Indications}

The most common indication in the groups in terms of the hysterectomy, was found to be myoma uteri. Indications for hysterectomy are presented in Table 4. The second most common indication was found to be treatment-resistant menometrorrhagia. Treatmentresistant menometrorrhagia was statistically higher in the nodular adenomyosis compared to diffuse adenomyosis [32.4\% (95\% CI:21.7-43.0) vs. 16.1\% (95\% CI:13.318.8)] $(P=0.001)$. When patients with a presumed diagnosis of endometrial pathology were evaluated, diffuse adenomyosis was more likely to be reported in the histopathological examination [24.8\% (95\% CI:21.5$28.0)$ vs. $6.8 \%$ (95\% CI: $1.0-12.5)](P=0.001)$. However, no significant difference was observed between the two groups in terms of other surgery indications $[5.1 \%$ (95\% CI: $3.4-6.7$ ) vs. $2.7 \%$ (95\% CI: 0-6.3)] (Table 4).

\section{Preoperative Endometrial Histopathology and Coexisting Pathologies}

The histopathological outcomes of preoperative endometrial biopsy specimens are presented in Table 5. Adenomyosis was accompanied by endometrial polyps in $11.2 \%$ of the patients, endometrial hyperplasia in $12.2 \%$, atrophic endometrium in $2.5 \%$, endometrial carcinoma in $0.8 \%$, proliferative phase endometrium in $21.7 \%$, secretion phase endometrium in $15.2 \%$, irregular proliferative endometrium in $9.8 \%$ and nonspecific endometrial pathologies (inactive endometrium, chronic nonspesific endometrium and autolytic endometrium) in $5.7 \%$ of the patients. The pathologic condition with the highest probability to be associated with adenomyosis was found to be myoma uteri $(\mathrm{n}=455,60.2 \%)$. When

Table 1. Age, Gravidity, Parity and Endometrial Thickness Values of Patients with Diffuse and Nodular Adenomyosis

\begin{tabular}{|c|c|c|c|c|}
\hline & Total & Diffuse Adenomyosis & Nodular Adenomyosis & \multirow{2}{*}{ P-Value** } \\
\hline & Mean \pm SD $(\text { Min-Max })^{*}$ & Mean \pm SD $($ Min-Max $)$ & Mean \pm SD (Min-Max $)$ & \\
\hline Age & $50 \pm 5.7(35-77)$ & $50.1 \pm 5.7(38-77)$ & $49.5 \pm 6.0(35-71)$ & 0.451 \\
\hline Gravidity & $4.2 \pm 2.4(0-16)$ & $4.2 \pm 2.5(0-16)$ & $4.3 \pm 2.3(1-10)$ & 0.952 \\
\hline Parity & $2.9 \pm 1.4(0-8)$ & $2.9 \pm 1.4(0-8)$ & $2.9 \pm 1.3(1-6)$ & 0.955 \\
\hline Endometrial thickness & $9.5 \pm 4.3(1-32)$ & $9.6 \pm 4.4(1-32)$ & $9.6 \pm 4.4(3-25)$ & 0.753 \\
\hline
\end{tabular}

*Descriptive Statistics; **Independent Samples $t$ test.

Table 2. Complaints of Patients with Histopathological Diagnosis of Diffuse and Nodular Adenomyosis

\begin{tabular}{|c|c|c|c|}
\hline & $\begin{array}{l}\text { Diffuse Adenomyosis } \\
(n=681)\end{array}$ & $\begin{array}{l}\text { Nodular Adenomyosis } \\
\qquad(\mathrm{n}=74)\end{array}$ & $P$ Value* \\
\hline & n/CI (95\% Confidence Interval) & n/CI (95\% Confidence Interval) & \\
\hline \multicolumn{4}{|c|}{ AUB $n=336(44.5 \%)$} \\
\hline Present & $294 /(39.3-46.8)$ & $42 /(45.4-67.9)$ & 0.027 \\
\hline Absent & $387 /(53.1-60.6)$ & $32 /(32.0-54.5)$ & \\
\hline \multicolumn{4}{|c|}{ Pelvic pain $n=139(18.4 \%)$} \\
\hline Present & $127(15.6-21.5)$ & $13(8.8-26.1)$ & 1.000 \\
\hline Absent & $554(78.4-84.3)$ & $61(73.8-91.1)$ & \\
\hline \multicolumn{4}{|c|}{ PMVB $n=119(15.7 \%)$} \\
\hline Present & $109(13.2-18.7)$ & $10(5.7-21.3)$ & 0.737 \\
\hline Absent & $572(81.2-86.7)$ & $64(78.7-94.2)$ & \\
\hline \multicolumn{4}{|c|}{ Asymptomatic $n=163(21.4 \%)$} \\
\hline Present & $156(19.7-26.0)$ & $5(1.0-12.3)$ & 0.001 \\
\hline Absent & $525(73.9-80.2)$ & $69(87.6-98.9)$ & \\
\hline
\end{tabular}

PMVB, Postmenopausal vaginal bleeding; AUB, Abnormal uterine bleeding.

* Chi-Square test. 
Table 3. Complaints of Patients with Histopathological Diagnosis of Diffuse and Nodular Adenomyosis with and without Coexisting Pathologies

\begin{tabular}{|c|c|c|c|}
\hline \multirow{2}{*}{$\begin{array}{l}\text { Diffuse Adenomyosis } \\
(\mathrm{n}=681)\end{array}$} & $\begin{array}{l}\text { Single Adenomyosis } \\
\quad(n=106)\end{array}$ & $\begin{array}{l}\text { Adenomyosis with other Pathologies } \\
\qquad(\mathrm{n}=649)\end{array}$ & \multirow{2}{*}{$\begin{array}{c}P \\
\text { Value* }\end{array}$} \\
\hline & $\begin{array}{c}n=75 \\
n / C I(95 \% \text { Confidence Interval) }\end{array}$ & $\begin{array}{c}n=606 \\
n / C I(95 \% \text { Confidence Interval) }\end{array}$ & \\
\hline \multicolumn{4}{|l|}{ AUB } \\
\hline Present & $28 /(26.3-48.2)$ & $266 /(39.8-47.7)$ & 0.323 \\
\hline Absent & $47 /(51.7-73.6)$ & $340 /(52.2-60.1)$ & \\
\hline \multicolumn{4}{|l|}{ Pelvic pain } \\
\hline Present & $16 /(12.0-30.5)$ & $111 /(15.2-21.3)$ & 0.531 \\
\hline Absent & $59 /(69.4-87.9)$ & 495/(78.6-84.7) & \\
\hline \multicolumn{4}{|l|}{ PMVB } \\
\hline Present & $14 /(9.8-27.3)$ & $94 /(12.6-18.3)$ & 0.503 \\
\hline Absent & $61 /(72.5-90.2)$ & $512 /(81.6-87.3)$ & \\
\hline \multicolumn{4}{|l|}{ Asymptomatic } \\
\hline Present & $0 /(0.0 \%)$ & $156 /(22.2-29.1)$ & 0.001 \\
\hline Absent & $75 /(100 \%)$ & $450 /(70.8-77.7)$ & \\
\hline Nodular Adenomyosis $(n=74)$ & $\begin{array}{c}(\mathrm{n}=31) \\
\mathrm{n} / \mathrm{Cl}(95 \% \text { Confidence Interval })\end{array}$ & $\begin{array}{c}(n=43) \\
n / C I(95 \% \text { Confidence Interval })\end{array}$ & $\begin{array}{c}P \\
\text { Value* }\end{array}$ \\
\hline \multicolumn{4}{|l|}{ AUB } \\
\hline Present & 16/(34.0-69.1) & $26 /(45.7-75.0)$ & 0.484 \\
\hline Absent & $15 /(30.8-65.9)$ & $17 /(24.9-54.2)$ & \\
\hline \multicolumn{4}{|l|}{ Pelvic pain } \\
\hline Present & 9/(13.0-44.9) & $4 /(0.62-17.9)$ & 0.028 \\
\hline Absent & $22 /(55.0-86.9)$ & 39/(82.0-99.3) & \\
\hline \multicolumn{4}{|l|}{ PMVB } \\
\hline Present & $3 /(0-19.9)$ & $7 /(5.2-27.1)$ & 0.505 \\
\hline Absent & $28 /(80-100)$ & $36 /(72.7-94.8)$ & \\
\hline \multicolumn{4}{|l|}{ Asymptomatic } \\
\hline Present & $2 /(0-14.9)$ & $3 /(0-14.4)$ & 1.000 \\
\hline Absent & 29/(84.9-100) & $40 /(85.5-100)$ & \\
\hline
\end{tabular}

PMVB, Postmenopausal vaginal bleeding; AUB, Abnormal uterine bleeding.

* Chi-square test.

diffuse and nodular adenomyosis were compared in terms of the endometrial pathologies, the association of endometrial hyperplasia with diffuse adenomyosis was more common than the association of endometrial hyperplasia with nodular adenomyosis $(P<0.02)$. With respect to menopausal status, association with endometrial hyperplasia was more common in the diffuse adenomyosis cases in premenopausal patients $(16.8 \%-5.3 \%)$. When a comparison was made for endometrial polyp, endometrial cancer, and atrophic endometrium, which are among the other pathologies, no statistically significant difference was found between the two groups $(P>0.05)$ (Table 5). The association of malignancy and adenomyosis rate was $0.8 \%$. The six malignancy cases $(0.8 \%)$ identified were in association with diffuse adenomyosis. All of these cases were early-stage grade 1 endometrioid adenocarcinomas.

\section{Discussion}

Data about the incidence, clinical presentation, association with gynecological diseases and the relationship with endometrial, uterine and extrauterine pathologies is insufficient for comparison of nodular and diffuse adenomyosis. To our knowledge, this is one of the rare studies investigating the clinical differences between nodular and diffuse adenomyosis. One of the most important results of this study was regarding the incidence of symptomatology and histopathological evaluation of nodular adenomyosis in a single center with a large case number. The rate of diffuse adenomyosis was found to be $91.2 \%$, and the rate of nodular adenomyosis was $9.8 \%$ in our series. The second important result was the documentation of different presenting complaints in two types of adenomyosis. When concomitant pathologies were excluded, the most common symptom was found to be AUB in pure nodular adenomyosis patients; however, only pelvic pain was found to be statistically significant in pure nodular adenomyosis compared to pure diffuse adenomyosis. 
Table 4. Hysterectomy Indications of Patients with Histopathological Diagnosis of Diffuse and Nodular Adenomyosis

\begin{tabular}{|c|c|c|c|}
\hline & $\begin{array}{l}\text { Diffuse Adenomyosis } \\
(\mathbf{n}=\mathbf{6 8 1})\end{array}$ & $\begin{array}{l}\text { Nodular Adenomyosis } \\
(\mathrm{n}=74)\end{array}$ & $P$ \\
\hline & $\begin{array}{c}\mathrm{n} / \mathrm{Cl} \text { (95\% Confidence } \\
\text { Interval) }\end{array}$ & $\begin{array}{c}\text { n/CI (95\% Confidence } \\
\text { Interval) }\end{array}$ & Value* \\
\hline \multicolumn{4}{|c|}{ Myoma uteri } \\
\hline Present & $269 /(35.8-43.1)$ & $30 /(29.3-51.6)$ & \multirow[t]{2}{*}{0.901} \\
\hline Absent & $412 /(56.8-64.1)$ & $44 /(48.3-70.6)$ & \\
\hline \multicolumn{4}{|c|}{ Treatment refractory menometrorrhagia } \\
\hline Present & 110/(13.3-18.8) & $24 /(21.7-43.0)$ & \multirow[t]{2}{*}{0.001} \\
\hline Absent & $571 /(81.1-86.6)$ & $50 /(56.9-78.2)$ & \\
\hline \multicolumn{4}{|c|}{ Endometrial pathology } \\
\hline Present & $169 /(21.5-28.0)$ & $5 /(1.0-12.5)$ & \multirow[t]{2}{*}{0.001} \\
\hline Absent & $512 /(71.9-78.4)$ & 69/(87.4-98.9) & \\
\hline \multicolumn{4}{|c|}{ Endometrial hyperplasia } \\
\hline Present & $92 /(10.9-16.0)$ & $1 /(0-4.1)$ & \multirow[t]{2}{*}{0.001} \\
\hline Absent & $589 /(83.9-89.0)$ & 73/(95.9-100) & \\
\hline \multicolumn{4}{|c|}{ Endometrial Thickness } \\
\hline Present & 77/(8.9-13.6) & $4 /(0.2-10.5)$ & \multirow[t]{2}{*}{0.164} \\
\hline Absent & $604 /(86.3-91.0)$ & $70 /(89.4-99.7)$ & \\
\hline \multicolumn{4}{|c|}{ Pelvic pain } \\
\hline Present & $64 /(7.1-11.4)$ & $10 /(5.7-21.2)$ & \multirow[t]{2}{*}{0.300} \\
\hline Absent & $617 /(88.5-92.8)$ & $64 /(78.7-94.2)$ & \\
\hline \multicolumn{4}{|c|}{ Ovarian cyst } \\
\hline Present & $22 /(1.8-4.5)$ & $0 /(0 \%)$ & \multirow[t]{2}{*}{0.155} \\
\hline Absent & 659/(95.4-98.1) & $74 /(100 \%)$ & \\
\hline \multicolumn{4}{|c|}{ Pelvic mass } \\
\hline Present & $12 /(0.7-2.8)$ & $3 /(0-8.6)$ & \multirow[t]{2}{*}{0.175} \\
\hline Absent & 669/(97.2-99.1) & $71 /(91.3-100)$ & \\
\hline \multirow{2}{*}{ Other } & $35 /(3.4-6.7)$ & $2 /(0-6.3)$ & \multirow{2}{*}{1.000} \\
\hline & $646 /(93.2-96.5)$ & $72 /(93.6-100)$ & \\
\hline
\end{tabular}

* Chi-square test.

Several studies showed that the diagnosis of adenomyosis can be made by the combination of clinical history, gynecological examination, and transvaginal 2D and $3 \mathrm{D}$ ultrasound. ${ }^{10-13}$

Dakhly et al investigated the accuracy of endomyometrial biopsy obtained in office hysteroscopy for the histopathologic evidence of adenomyosis. In this study, the combination of transvaginal ultrasonography with hysteroscopic endomyometrial biopsy was found to increase specificity from $60 \%$ to $89 \% .^{13}$

A definitive diagnosis of adenomyosis can only be established via histopathological examination of the uterus. Since there has been no defined specific method or symptom for preoperative diagnosis of the disease, the reported incidences are based on the histopathologies of hysterectomy materials. Therefore, the prevalence varies widely among several reports. This rate is reported in the literature between $5 \%$ and $70 \% .{ }^{14,15}$ However, the average incidence is accepted to be about 20\%-30\%. ${ }^{16}$ In our study, the incidence of adenomyosis was found to be $21.8 \%$, which was similar to the generally accepted rate. Differences in incidence might be the result of several factors, including patient selection, variation in the selection of specimens, awareness of pathologists about this diagnosis, the number of the sections in the specimen, and the variations in histologic criteria. Since this was a single-center study and there was no variation in histological criteria, histopathological evaluation limitations were minimal.

The pathophysiological basis of adenomyosis is still poorly understood and estrogen is known to be an important factor in the pathogenesis. Some studies have shown the association of estrogen with adenomyosis, polyp and leiomyoma at the macro and micro levels. ${ }^{17}$ In a recent study with a relatively large sample size, $\mathrm{Li}$ et al also confirmed this association. ${ }^{18}$ However, in Li's study, the percentage of menopausal patients was very low $(3.3 \%)$. On the other hand, $28.7 \%$ of the patients were in the menopausal period with a mean age of 56.6 years in the present study. Our data indicated that $36.1 \%$ 
Table 5. Available Preoperative Endometrial Biopsy Results of Patients with Histopathological Diagnosis of Diffuse and Nodular Adenomyosis

\begin{tabular}{|c|c|c|c|}
\hline & $\begin{array}{l}\text { Diffuse Adenomyosis } \\
\qquad(\mathbf{n}=\mathbf{6 8 1})\end{array}$ & $\begin{array}{l}\text { Nodular Adenomyosis } \\
\qquad(\mathrm{n}=74)\end{array}$ & \multirow[t]{2}{*}{$P$ Value* } \\
\hline & n/CI (95\% Confidence Interval) & n/CI (95\% Confidence Interval) & \\
\hline \multicolumn{4}{|l|}{ Bx PE } \\
\hline Present & $147 /(18.4-24.5)$ & $17 /(13.3-32.4)$ & 0.768 \\
\hline Absent & $534 /(75.4-81.5)$ & $57 /(67.5-86.6)$ & \\
\hline \multicolumn{4}{|l|}{ Bx SE } \\
\hline Present & 105/(12.6-18.1) & $16 /(12.2-30.9)$ & 0.181 \\
\hline Absent & $576 /(81.8-87.3)$ & $58 /(69.0-87.7)$ & \\
\hline \multicolumn{4}{|l|}{ Bx IPE } \\
\hline Present & $86 /(10.1-15.0)$ & $7 /(2.8-16.1)$ & 0.576 \\
\hline Absent & 595/(84.9-89.8) & $67 /(83.8-97.1)$ & \\
\hline \multicolumn{4}{|c|}{ Bx endometrial polyp } \\
\hline Present & $81 /(9.3-14.2)$ & $11 /(6.7-22.8)$ & 0.455 \\
\hline Absent & 600/(85.7-90.6) & 63/(77.1-93.2) & \\
\hline \multicolumn{4}{|c|}{ Bx Endometrial hyperplasia } \\
\hline Present & $102 /(12.2-17.5)$ & $4 /(0.2-10.5)$ & 0.022 \\
\hline Absent & $579 /(82.4-87.7)$ & 70/(89.4-99.7) & \\
\hline \multicolumn{4}{|c|}{ Bx endometrial cancer } \\
\hline Present & $6 /(0.1-1.4)$ & $0 /(0.0 \%)$ & 1.000 \\
\hline Absent & 675/(98.5-99.8) & 74/(100 \%) & \\
\hline \multicolumn{4}{|c|}{ Bx atrophic Endometrium } \\
\hline Present & $21 /(1.79-4.4)$ & $2 /(0-6.3)$ & 1.000 \\
\hline Absent & $660 /(95.5-98.2)$ & $72 /(93.6-100)$ & \\
\hline
\end{tabular}

Bx, Biopsy; PE, Proliferative endometrium; SE, Secretory endometrium; IPE, Irregular proliferative endometrium.

* Chi-square test.

of the patients diagnosed with adenomyosis were in the age range of 50-60 years. Evaluation of menopausal and premenopausal periods separately revealed no significant difference between the groups regarding the presence of uterine or endometrial pathologies (myoma, polyp and malignancies), which are known to play a role in estrogen activation. Interestingly, a subgroup analysis of the premenopausal women revealed that the incidence of endometrial hyperplasia was significantly higher in the diffuse adenomyosis group compared to the nodular adenomyosis group. This association was not observed in the postmenopausal population.

Adenomyosis has a high probability to be incidentally detected on postoperative histopathological examination. Therefore, one can wonder if the rate of performed hysterectomies might affect the reported prevalence of adenomyosis. It is not surprising that the rate of performed hysterectomies due to various reasons increases in patients with age, resulting in an increased likelihood of diagnosing incidental adenomyosis. In a study investigating hysterectomy practices, hysterectomy rates were reported to be similar to the age-specific rates of adenomyosis that we found in this study. ${ }^{19}$ In that study, while the hysterectomy rate was found to be $55.7 \%$ in the fourth decade of life, the rate in the fifth decade was $30.5 \%$. This rate was consistent with the rates in our study. In our study, the prevalence of adenomyosis was found to be $2.3 \%$ in patients under 40 years of age, while this rate was $4.2 \%$ in those above 60 years. The rate of adenomyosis was found to be $56.4 \%$ in the $40-50$-year-old and $36.1 \%$ in the $50-60$-year-old age group. Interestingly, we did not find a significant difference in the distribution of adenomyosis types between the age groups. This result indicates that increasing age does not have an impact on the type of adenomyosis.

Adenomyosis is known as a disease in premenopausal and fertile women and usually develops in multiparous patients. ${ }^{4,18}$ Other clinical trials reported that the incidence of adenomyosis increased in multiparous patients and pregnancy was a risk factor. ${ }^{20-22}$ Additionally, dilatation and curettages, cesarean section and hysteroscopic uterine surgeries were found to deteriorate the integrity of the endometrial-myometrial junction, leading to the formation of adenomyosis. ${ }^{14,23}$ According to adenomyosis formation theories, all myometrial lesions may be examples of invagination and the transportation of the endometrial cells. Furthermore, in vitro studies have shown endometrial cells to be pluripotent and have invasive abilities. ${ }^{24}$

The most common theory claimed that adenomyosis 
results from invagination of the endometrial basalis into the myometrium which results in tissue injury and repair mechanism. An alternative theory stated that adenomyotic lesions result from metaplasia of displaced embryonic pluripotent Müllerian remnants or differentiation of adult stem cells. $^{25}$

The theory of the deterioration of the endometrialmyometrial junction was also supported by our results. In our study, the majority of both diffuse and nodular adenomyosis patients were multiparous. However, no significant difference was observed between diffuse and nodular adenomyosis groups in terms of parity, gravidity and previous uterine surgery or curettage.

Adenomyosis may cause diverse symptoms such as AUB, painful menstruation, cyclic or noncyclic pelvic pain, pelvic compression and dyspareunia; however, none of these symptoms are specific to adenomyosis. ${ }^{5}$ Complaints of AUB (premenopausal AUB and treatment-resistant meno-metrorrhagia) and pelvic pain were found to be prominent in the majority of our patients. Interestingly, AUB was observed to be more common in nodular adenomyosis than the diffuse form. This could be due to the mechanical effect of nodular adenomyosis on the functional endometrium, the expansion of the endometrial surface area and loss of the synchronized contractility ability of the adenomyotic uterus or the effects of concomitant pathology. Moreover, the prevalence of AUB, pelvic pain and postmenopausal vaginal bleeding did not differ significantly when the adenomyosis-only group was compared with adenomyosis plus other pathologies. On the other hand, with respect to postmenopausal bleeding, no significant difference was found between nodular and diffuse adenomyosis groups.

Pelvic pain was one of the interesting results of this study. Although there was not a significant difference between the groups, when co-existing pathologies were excluded, pelvic pain was found to be more common in nodular adenomyosis. Similarly, Chen et al reported a study of some characteristics related to pain manifestation and, more specifically, dysmenorrhea in patients with adenomyosis. ${ }^{26}$

In the literature, $23.9 \%-35 \%$ of the patients diagnosed with adenomyosis were reported to be asymptomatic..$^{27,28}$ In our study, the rate of asymptomatic patients was found to be $21.3 \%$. The majority of asymptomatic patients consisted of diffuse adenomyosis cases. When diffuse and nodular adenomyosis were compared, $22.3 \%(n=152)$ of diffuse and $12.2 \%(n=9)$ of nodular adenomyosis patients were asymptomatic; this difference was statistically significant. It seems reasonable to conclude that asymptomatic endometrial pathologies are more common with diffuse adenomyosis and the patients usually undergo hysterectomies for this reason.

Our histopathologic findings were similar to the results of the study by Saleh et al. ${ }^{29}$ In our study, endometrial pathologies, especially endometrial hyperplasia, were more common in diffuse adenomyosis patients, while endometrioid adenocarcinoma was not observed with nodular adenomyosis. Endometrial carcinomas detected with adenomyosis were reported to be early-stage and lowgrade hormone sensitive tumors with a good prognosis. ${ }^{27}$

In one study, out of 229 cases of endometrial cancer, 64 patients $(28 \%)$ had concurrent endometrial cancer and adenomyosis. Among these 64 patients, 7 (11\%) had a malignant transformation of adenomyosis. ${ }^{30}$ In our study, endometrial carcinoma was found in $0.8 \%$ of patients with diffuse adenomyosis and all cases were early-stage, lowgrade hormone sensitive tumors. However, the number of our cases was relatively insufficient to make a general statement.

Inconsistency between clinical and pathological diagnosis seems to be one of the most prominent obstacles in gynecology. Therefore, any clinical clue or laboratory parameter that might have a preoperative value for predicting adenomyosis would have a great impact on the evaluation and differential diagnosis of this entity. The most common USG finding in our study was heterogeneity detected in the uterus. However, no statistically significant difference was found between the two adenomyosis types in terms of the USG findings. However, Chen et al reported that the symptoms of pain together with obvious elevation of CA125 and rectal irritation as well as thickened myometrial layer on TVUS may be regarded as clues for clinicians when dealing with adenomyosis. A clinical model based on these symptoms may improve the preoperative diagnosis rate of adenomyosis. ${ }^{26}$

Preservation of the uterus is important in young patients and especially in those who desire future fertility. Excision of the adenomyotic focus is known to be challenging in terms of the operation technique in nodular adenomyosis patients, who undergo surgery due to a presumed diagnosis of myoma uteri. Such cases may result in hysterectomy. Some authors found that the mean age of the adenomyosis cases was as low as 41 to 44 years of age. ${ }^{31,32}$ Therefore, preoperative suspicion becomes important in young patients, especially those who have a uterine mass. We suggest that young patients who present with complaints of AUB and pain, with a mass detected on sonography in the uterus, and proven not to have endometrial pathology should be evaluated more sensitively in order to facilitate documentation of any clues for the distinction of nodular adenomyoma and myoma before making a decision for operation. Future studies utilizing new techniques such as elastography or diffusion MRI for distinction of nodular adenomyosis in young women with the desire of fertility may provide new insights for the management of such patients.

A possible concomitant adenomyosis disease should be considered when aggravation of the symptoms occurs or in case of treatment failure in patients with accompanying pathologies such as endometrial polyps, submucous myoma, and endometrial hyperplasia. 


\section{Conflict of Interest Disclosures}

We have no conflicts of interest. We have no financial relationship with the organization that sponsored the research and we have had full control of all primary data and we agree to allow the Journal to review their data if requested.

\section{Ethical Statement}

The study was conducted in accordance with the Declaration of Helsinki, and the protocol was approved by the Ethics Committee of number $2020 / 12-23$ on 12.10 .2020 .

\section{Authors' Contributions}

GSD designed the study, collected the data, statistically analyze the data, wrote the paper. IU analyzed the manuscript, analyzed the data, edited the language.

\section{References}

1. Rokitansky K. Über Uterusdrüsen-Neubildung. Z Gesellschaft Aerzte. 1980. Available from: https:// wellcomecollection.org/works/xv5k8nzn.

2. CullenTS.Adenomyoma oftheuterus.JAMA.1908;L(2):10715. doi:10.1001/jama.1908.25310280023002d.

3. Zaloudek C, Hendrickson MR. Mesenchymal tumors of theuterus. In: Kurman RJ, eds. Blausteins' Pathology of the Female Genital Tract. 5th ed. New York: Springer; 2002:561-73.

4. Azziz R. Adenomyosis: Current perspectives. Obstet Gynecol Clin North Am. 1989;16(1):221-35.

5. McElin TW, Bird CC. Adenomyosis of the uterus. Obstet Gynecol Annu. 1974;3(0):425-41.

6. Atri M, Reinhold C, Mehio AR, Chapman WB, Bret PM. Adenomyozis: US features with histologic correlation in an in vitro study. Radiology. 2000;215(3):783-90. doi: 10.1148/ radiology.215.3.r00jn06783.

7. Kunz G, Beil D, Huppert P, Noe M, Kissler S, Leyendecker G. Adenomyosis in endometriosis prevalence and impact on fertility. Evidence from magnetic resonance imaging. Hum Reprod. 2005;20(8):2309-16. doi: 10.1093/humrep/ dei021.

8. Benagiano G, Brosens I. The endometrium in adenomyosis. Womens Health (Lond). 2012;8(3):301-12. doi: 10.2217/ whe.12.8.

9. Reinhold C, Tafazoli F, Wang L. Imaging features of adenomyosis. Hum Reprod Update. 1998;4(4):337-49. doi: 10.1093/humupd/4.4.337.

10. Andres MP, Borrelli GM, Ribeiro J, Baracat EC, Abrão MS, Kho RM. Transvaginal Ultrasound for the Diagnosis of Adenomyosis: Systematic Review and Meta-Analysis. J Minim Invasive Gynecol. 2018;25(2):257-64. doi: 10.1016/j. jmig.2017.08.653.

11. Dartmouth K. A systematic review with metaanalysis: The common sonographic characteristics of adenomyosis. Ultrasound. $2014 \quad ; 22(3): 148-57 . \quad$ doi: 10.1177/1742271X14528837.

12. Dueholm M. Transvaginal ultrasound for diagnosis of adenomyosis: a review. Best Pract Res Clin Obstet Gynaecol. 2006 ;20(4):569-82. doi: 10.1016/j.bpobgyn.2006.01.005.

13. Dakhly DMR, Abdel Moety GAF, Saber W, Gad Allah SH, Hashem AT, Abdel Salam LOE. Accuracy of Hysteroscopic
Endomyometrial Biopsy in Diagnosis of Adenomyosis. J Minim Invasive Gynecol. 2016;23(3):364-71. doi: 10.1016/j. jmig.2015.11.004.

14. Leyendecker G, Wildt L, Mall G. The pathophysiology of endometriosis and adenomyosis: tissue injury and repair. Arch Gynecol Obstet. 2009;280(4):529-38. doi: 10.1007/ s00404-009-1191-0.

15. Indraccolo U, Barbieri F. Relationship between adenomyosis and uterine polyps. Eur J Obstet Gynecol Reprod Biol. 2011;157(2):185-9. doi: 10.1016/j.ejogrb.2011.02.014.

16. Vercellini P, Parazzini F, Oldani S, Panazza S, Bramante T, Crosignani PG. Adenomyosis at hysterectomy: a study on frequency distribution and patient characteristics. Hum Reprod. 1995;10(5):1160-2. doi: 10.1093/oxfordjournals. humrep.a136111.

17. Parazzini F, Vercellini P, Pazza S, Chatenoud L, Oldani S, Crosignani PG. Risk factors for adenomyosis. Hum Reprod. 1997;12(6):1275-9. doi: 10.1093/humrep/12.6.1275.

18. Li X, Liu X, Guo SW. Clinical profiles of 710 premenopausal women with adenomyosis who underwent hysterectomy. J Obstet Gynaecol Res. 2014;40(2):485-94. doi: 10.1111/ jog. 12211.

19. Kıran Gökçe, FG. Pathologic evaluation of total hysterectomy materials performed in our hospital between 2008-2009. 2009. Available from: http://www.istanbulsaglik.gov.tr/w/ tez/pdf/aile_hekimligi/dr_fatma_gulsah_kiran_gokce.pdf.

20. Bergholt T, Eriksen L, Berendt N, Jacobsen M, Hertz JB. Prevalence and risk factors of adenomyosis at hysterectomy. Hum Reprod. 2001;16(11):2418-21. doi: 10.1093/ humrep/16.11.2418.

21. Levgur M, Abdai MA, Tucker A. Adenomyosis: symptoms, histology, and pregnancy terminations. Obstet Gynecol. 2000;95(5):688-91. doi: 10.1016/s0029-7844(99)00659-6.

22. Genc $M$, Genc B, Cengiz $H$. Adenomyosis and accompanying gynecological pathologies. Arch Gynecol Obstet. 2015;291(4):877-81. doi: 10.1007/s00404-0143498-8.

23. Boeer B, Wallwiener M, Rom J, Schoenfisch B, Brucker SY, Taran FA. Differences in the clinical phenotype of adenomyosis and leiomyomas: a retrospective, questionnaire-based study Arch Gynecol Obstet. 2014;289(6):1235-39. doi: 10.1007/s00404-013-3141-0.

24. Bergeron C, Amant F, Ferenczy A. Pathology and physiopathology of adenomyosis. Best Pract Res Clin Obstet Gynaecol. 2006;20(4):511-21. doi: 10.1016/j. bpobgyn.2006.01.016.

25. García-Solares J, Donnez J, Donnez O, Dolmans MM. Pathogenesis of uterine adenomyosis: invagination or metaplasia? Fertil Steril. 2018;109(3):371-9. doi: 10.1016/j. fertnstert.2017.12.030.

26. Chen Q, Li YW, Wang S, Fan QB, Shi HH, Leng JH, et al. Clinical manifestations of adenomyosis patients with or without pain symptoms. J Pain Res. 2019;12:3127-33. doi: 10.2147/JPR.S212117.

27. Peric H, Fraser IS. The symptomatology of adenomyosis. Best Pract Res Clin Obstet Gynaecol. 2006;20(4):547-55. doi: 10.1016/j.bpobgyn.2006.01.006.

28. Levy G, Dehaene A, Laurent N,Lernout M, Collinet P, Lucot JP, et al. An update on adenomyosis. 2013;94(1):3-25. doi: 10.1016/j.diii.2012.10.012 
29. Saleh SS, Fram K. Histopathology diagnosis in women who underwent a hysterectomy for a benign condition. Arch Gynecol Obstet. 2012;285(5):1339-43. doi: 10.1007/s00404011-2152-y.

30. Zouzoulas OD, Tsolakidis D, Efstratiou I, Pervana S, Pazarli E, Grimbizis G. Correlation between Adenomyosis and Endometrial cancer: 6-year experience of a single center. Facts Views Vis Obgyn. 2018;10(3):147-52.

31. Taran FA, Wallwiener M, Kabashi D, Rothmund
R, Rall K, Kraemer B, et al. Clinical characteristics indicating adenomyosis at the time of hysterectomy: a retrospective study in 291 patients. Arch Gynecol Obstet. 2012;285(6):1571-6. doi: 10.1007/s00404-011-2180-7.

32. Taran FA, Weaver AL, Coddington CC, Stewart EA. Understanding adenomyosis: a case control study. Fertil Steril. 2010:94(4):1223-8. doi: 10.1016/j. fertnstert.2009.06.049. 